University of Nebraska - Lincoln

DigitalCommons@University of Nebraska - Lincoln

March 2005

\title{
Evaluating sex offenders under sexually violent predator laws: How might mental health professionals conceptualize the notion of volitional impairment?
}

\author{
Cynthia Calkins Mercado \\ University of South Florida, cc_mercado@yahoo.com \\ Robert F. Schopp \\ University of Nebraska College of Law, rschopp1@unl.edu \\ Brian H. Bornstein \\ University of Nebraska-Lincoln, bbornstein2@unl.edu
}

Follow this and additional works at: https://digitalcommons.unl.edu/psychfacpub

Part of the Psychiatry and Psychology Commons

\begin{abstract}
Mercado, Cynthia Calkins; Schopp, Robert F.; and Bornstein, Brian H., "Evaluating sex offenders under sexually violent predator laws: How might mental health professionals conceptualize the notion of volitional impairment?" (2005). Faculty Publications, Department of Psychology. 157.

https://digitalcommons.unl.edu/psychfacpub/157
\end{abstract}

This Article is brought to you for free and open access by the Psychology, Department of at DigitalCommons@University of Nebraska - Lincoln. It has been accepted for inclusion in Faculty Publications, Department of Psychology by an authorized administrator of DigitalCommons@University of Nebraska - Lincoln. 


\title{
Evaluating sex offenders under sexually violent predator laws: How might mental health professionals conceptualize the notion of volitional impairment?
}

\author{
Cynthia Calkins Mercado, Robert F. Schopp, and Brian H. Bornstein \\ Law Psychology Program, University of Nebraska-Lincoln
}

Submitted February 2003; revised September 2003; accepted December 2003; available online 13 December 2004.

\begin{abstract}
This paper examines the significance of the Supreme Court's Hendricks and Crane decisions, with focus given to how mental health professionals may conceptualize the notion of volitional impairment. The Hendricks decision authorized postsentence civil commitment for sex offenders having a mental abnormality or personality disorder, rendering them likely to engage in future acts of sexual violence. In the Supreme Court's majority opinion, Justice Thomas implied that the Kansas Act was legitimized by limiting the class of offenders eligible for this specialized form of commitment to those who are "unable to control" their dangerousness. In Crane, the Court ruled that while the Hendricks decision does not require that a sex offender be completely unable to control behavior, it does require proof of serious difficulty in controlling conduct. In evaluating the meaning of this decision for mental health professionals, this paper notes the decline of volitional impairment standards in the insanity defense, summarizes case law regarding sexual predators and volitional impairment, and further reviews the empirical and theoretical literatures exploring the notion of volitional impairment.
\end{abstract}

Keywords: Volitional impairment, Control, Sex offender, Hendricks, Crane 


\section{Contents}

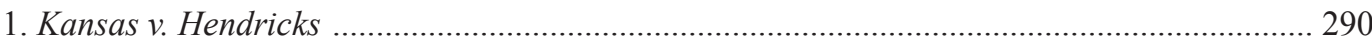

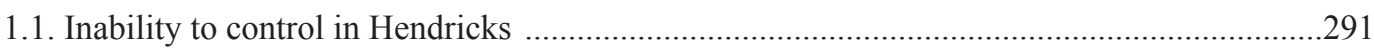

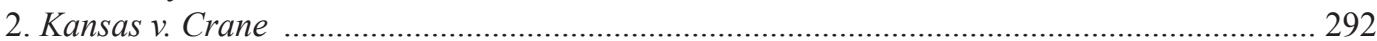

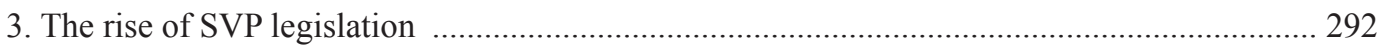

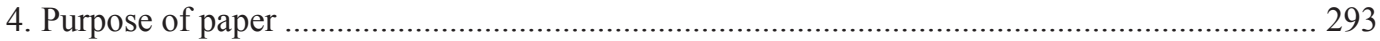

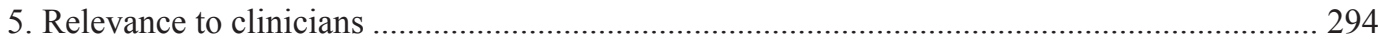

5.1. A brief history of the insanity defense and volitional impairment .....................................296

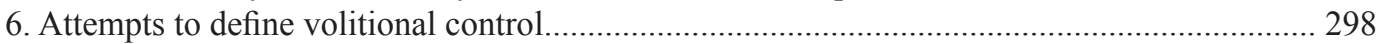

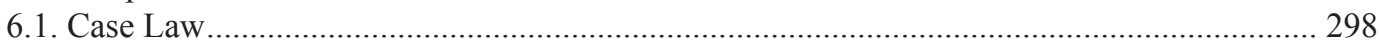

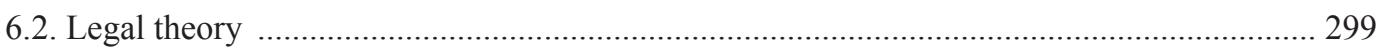

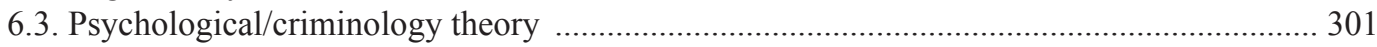

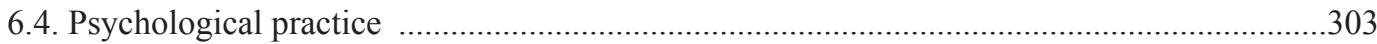

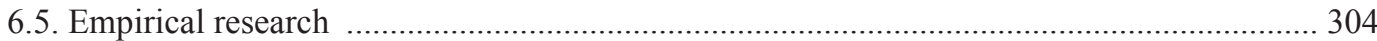

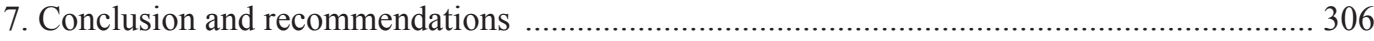

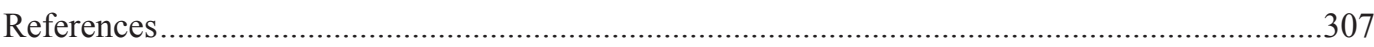

\section{Kansas v. Hendricks}

In Kansas v. Hendricks (1997), the United States Supreme Court, in a 5-4 decision, upheld a Kansas law establishing procedures for the indefinite civil commitment of persons found to have a "mental abnormality" or "personality disorder," rendering them likely to engage in "predatory acts of sexual violence." This decision, allowing indeterminate civil commitment for certain sex offenders after completion of a prison sentence, is reflective of one of society's most recent attempts to protect the public by preventing repeat occurrences of these particularly chilling (as Justice Thomas, author of the majority opinion, referred to the behavior in Hendricks) sexually deviant offenses.

In 1994, the Kansas legislature enacted a comprehensive scheme for the commitment of sexually violent predators due to their "likelihood of engaging in repeat acts of predatory sexual violence" (In re Hendricks, 1996). This Sexually Violent Predator (SVP) Act was modeled after legislation enacted in Washington in 1990, which was similarly devised to deal with the problem of repeat sex offenders. The State of Kansas sought to use its SVP Act for the first time on Leroy Hendricks, a prisoner with an extensive history of sexually assaultive behavior.

Undoubtedly, Hendricks' nearly 40-year history of sexual misconduct was precisely the type that lawmakers wanted to control. In 1994, at the time the civil commitment petition was filed, Hendricks had served 10 years of his 5- to 20-year sentence and was scheduled to be released to a halfway house (In re Hendricks, 1996). At trial, Hendricks acknowledged that he is a pedophile and testified to the fact that when he gets stressed out, he is unable to control the urge to sexually molest children (In re Hendricks, 1996). Moreover, despite a verbalized realization that his deviant acts are harmful to children, and his professed hope not to commit further assaults, he remarked that the only way to ensure that he would not reassault was "to die" (In re Hendricks, 1996). 
Under the Kansas statute, civil commitment requires that the state demonstrate that the sexual offender suffers from a mental abnormality or personality disorder and that this disorder renders the offender likely to commit sexual offenses (K.S.A. §59-29a02, 1994). At trial, the jury found beyond a reasonable doubt that Hendricks qualified as a SVP, based upon the facts that Hendricks "suffers from pedophilia" and "continues to harbor sexual desires toward children," which he admittedly cannot control when "stressed out" (Kansas v. Hendricks, 1997).

\subsection{Inability to control in Hendricks}

In Hendricks (1997), the majority seemed to view the inability to control behavior as a particular form of mental abnormality that legitimized Hendricks' commitment. Justice Thomas, who delivered the opinion of the Court, mentioned specifically that a finding of volitional impairment serves to limit involuntary civil commitment "in that it narrows the class of persons eligible for confinement to those who are unable to control their dangerousness" (Kansas v. Hendricks, 1997). Indeed, throughout the majority opinion, Justice Thomas repeatedly referred to the notion of volitional impairment, noting that " $[\mathrm{t}]$ his admitted lack of volitional control, coupled with a prediction of future dangerousness adequately distinguishes Hendricks from other dangerous individuals who are more properly dealt with exclusively through the criminal justice system" (Kansas v. Hendricks, 1997).

Unfortunately, nowhere in the opinion did the Court choose to elucidate what is meant by this vague notion of volitional impairment. Instead, the Court appeared to rely largely upon Hendricks' own testimony (concerning loss of control when under stress) and prior criminal history (including repeated acts of sexual violence) to support the conclusion that he suffered such volitional impairment. That the Court relied on Hendricks' history of sexual deviance and proclamations is at best mere speculation, as nowhere in the record is there explicit note concerning why Hendricks is viewed as suffering a volitional impairment.

If the Court is relying, in part, upon Hendricks' history, there remains a paucity of information relevant to how the inability to control is anything more than criminal recidivism. Schopp (1998) comments that the fact that some individuals choose to act repeatedly upon aberrant desires provides no evidence of volitional impairment. Indeed, if mere history of sexual misconduct provides evidence of volitional impairment, we have no way of differentiating those offenders with bona fide loss of control from those who simply choose to violate social rules by repeatedly acting upon their criminal desires (Schopp, 1998).

Moreover, relying on Hendricks' own statements might be of questionable validity and reliability. Morse (1998) argues that subjective feelings of loss of control are not sufficient to establish that one is, in fact, out of control. Such subjective report, with the potential to be minimized or exaggerated to satisfy a legal threshold, is not a reliable or valid way to measure control problems (Morse, 1998). Because we are without a definition of the notion of volitional impairment, it is impossible to know for certain what criteria the court considered in finding that Hendricks was not in control of his actions. 


\section{Kansas v. Crane}

The Supreme Court clarified the unanswered question of whether Hendricks required volitional impairment in Kansas v. Crane (2002). In recognizing the impractical nature of an absolutist approach, Crane (2002) held that something less than an absolute lack of control is required. While the Court did not provide a precise description of what might qualify as something less than an absolute lack of control, they did note that those eligible for commitment will generally find it "particularly difficult to control their behavior" (WL 75609 at 5).

Crane, a repeat sex offender, was diagnosed with both pedophilia and antisocial personality disorder (Crane, 2002). At the commitment proceeding, Dr. Mabugat, a psychiatrist, gave opinion that Crane's behavior "was a combination of willful and uncontrollable behavior" (In re Crane, 2000, 7 P.3d at 290). While the record notes that Dr. Mabugat's testimony provides "evidence of some inability on Crane's part to control his behavior," the court opinion does not provide evidence for such explanation. Indeed, the opinion does not specify or provide description for the parts of his behavior that were uncontrollable nor does it explain the apparent contradiction that Crane's behavior was both willful and uncontrollable (In re Crane, 7 P.3d at 290). Nor does the opinion provide rationale for the State's experts finding that Crane's mental impairment "does not impair his volitional control to the degree he cannot control his dangerous behavior (In re Crane, 7 P.3d at 288). Thus, we are left without some reasonable understanding of what this notion means. Michael Crane, unlike Leroy Hendricks, did not claim to have volitional impairment. Like Hendricks, however, Crane also has a history of sexually deviant behavior.

Whether either of these factors helped to support the notion of some uncontrollable behavior is unclear, as the court opinion does not offer clear explanation of the basis of the experts' decisions nor describe how the pathology manifested by Crane affected his ability to control his conduct.

Indeed, Justice Scalia, joined by Justice Thomas in the dissenting opinion of Crane (2002), notes that the Court's lack of elaboration about the specific circumstances affecting volitional impairment leaves trial courts without direction as to how they are to charge the jury. The opinion notes that the Court most likely failed to elaborate because there simply is no satisfactory way to frame the notion of inability to control, adding that "to leave the law in such a state of utter indeterminancy" is clearly irresponsible.

\section{The rise of SVP legislation}

Earl Shriner, a repeat sex offender who raped and cut off the penis of a 7-year-old boy upon his prison release, prompted the State of Washington to take action to ensure that such offenders be effectively managed. In 1990, the Washington legislature established the Community Protection Act, which, along with increased penalties and required registration for sex offenders, included a new law for a specialized form of sex offender civil commitment (American Psychological Association [APA], 1999). While most civil commitment statutes authorize 
civil commitment as an alternative to sanction through the criminal justice system, the sexual predator statutes allow commitment at the end of the offender's prison term on the basis of prior criminal acts. Indeed, such legislation is targeted at individuals whose tendency to commit sexual offense has not diminished during the period that the offender was confined.

The Washington Sexually Violent Predator Statute, upheld by the Supreme Court of Washington (In re Young, 1993), has served as the prototype for numerous other recently enacted sex offender statutes. Typically, these laws include four elements: (1) a history of sexual violence, (2) a current mental disorder or "abnormality," (3) risk of future sex crimes, and (4) some form of connection between the mental disorder and the danger, such that the mental impairment predisposes the individual to future sexual violence or "makes" it likely that the future harm will occur (Janus, 2000). To date, over 15 states have adopted some variation of the Washington sexual predator law, allowing indeterminate commitment after completion of the prison term on the basis of future dangerousness.

These laws can also be differentiated from general civil commitment statutes on the basis of the overt act requirement. Ordinary civil commitment, for example, might be justified where there has been some evidence of decline in the offender's psychological capacities, indicating increased dangerousness during the period of the offender's confinement (Schopp, Scalora, \& Pearce, 1999). Under the newer statutes, there is no requirement that a sex offender has committed a recent overt act to initiate civil commitment proceedings. Quite the contrary, sexual predator statutes provide for commitment based partly on prior criminal acts without any evidence of increased dangerousness or heightened proclivity to commit sexual offenses (Schopp et al., 1999). Moreover, ordinary civil commitment generally requires proof of serious mental disorder (La Fond, 2000). The sexual predator statutes have been subject to criticism, as they allow civil commitment without the "serious impairment of orientation, consciousness, comprehension, reasoning, or reality testing" that ordinarily is necessary to support civil commitment (Schopp et al., 1999). For example, Dr. Charles Befort, a testifying psychologist in Hendricks, offered that Hendricks qualified for diagnoses of "personality trait disturbance, passiveaggressive personality, and pedophilia," types of impairment that generally fall below the threshold to support the mental illness requirement of civil commitment statutes. Although a $D S M-I V$ diagnosis is, in and of itself, never sufficient to support commitment, the types of disorders more likely to render one eligible for civil commitment are those that involve more severe impairment, such as schizophrenia or mental retardation.

\section{Purpose of paper}

Pratt (2000) suggests that sex offenders are being "pursued and punished with even more vigor than in the sexual psychopath era" (p. 143). Certainly, this specialized form of commitment seems to have widened the civil commitment net by increasing the number of sex offenders eligible for civil commitment. While the public may feel reassured in its safety, these laws have not been without controversy. The Hendricks majority rejected Hendricks' double 
jeopardy and ex post facto challenges, noting that the Kansas Act is civil, and not punitive, in nature (Kansas v. Hendricks, 1997). Justice Breyer, writing for the dissent in Hendricks, argued, however, that Hendricks' confinement is a violation of double jeopardy, noting that "it was not simply an effort to commit Hendricks civilly, but rather to inflict further punishment upon him." Justice Breyer further maintained that constitutional provisions against ex post facto law making prohibited the statute's application to Hendricks, who was already in prison when the law was enacted. Later cases have continued to challenge the law's constitutionality based upon procedural and substantive due process claims. For example, in Seling, the Supreme Court, in ruling that Washington's Sexually Violent Predator Statute was civil rather than criminal, precluded petitioner Andre Brigham Young's double jeopardy and ex post facto challenges (Seling v. Young, 2001; see, also, In re Linehan, 1999).

Because this paper seeks to examine facets of the law already in place rather than focusing on a constitutional analysis of whether the law should in fact be in place, a detailed review will not be given to analysis of ex post facto, double jeopardy, and substantive due process claims at issue in recent cases. Nor will focus be given to the implications of the widened civil commitment net, ostensibly resulting from the expanded types of mental impairment (e.g., antisocial conduct establishing a personality disorder) supporting involuntary commitment along with the lack of traditional overt act requirements (see La Fond, 2000). This paper will explore the notion of volitional impairment in an attempt to provide mental health professionals with a more complete understanding of the notion, through both an examination of its legal history as well as through an examination of multidisciplinary conceptualizations. Because there is no widely accepted or court offered conceptualization, this paper seeks not to provide a single uniform explanation but rather to inform clinicians as to the complexities involved in evaluating evidence of volitional impairment.

\section{Relevance to clinicians}

What, if any, relevance does the Supreme Court's holdings in Hendricks and Crane have for mental health professionals? ${ }^{1}$ For one, clinicians regularly provide expert testimony or report in hearings held to determine whether offenders meet civil commitment criteria (Schopp et al., 1999). In regard to the determinative criteria mentioned above, mental health professionals might be asked to provide information relevant to whether the subject of a commitment hearing has a mental abnormality or personality disorder, rendering him likely to commit a sexual offense. Moreover, they might be asked to provide clinical opinion relevant to an offender's volitional capacity. Certainly, with specified legal criteria provided by the courts, clinicians could communicate knowledge about observed personality characteristics or symptom patterns in a way that would assist the trier of fact in answering questions concerning whether Hendricks criteria are met.

${ }^{1}$ The terms "mental health professionals" and "clinicians" will be used interchangeably to refer to those psychologists, psychiatrists, or related professionals who routinely provide testimony or report to the court. 
Ordinarily, when an individual convicted of a sex crime is set to be released from prison, the state may file a petition claiming that such individual is a violent sexual predator (Seling v. Young, 2001). That filing initiates a process for determining whether a sex offender qualifies as an SVP, under a particular state's definition. The offender is typically provided with a probable cause hearing, counsel, experts, and the option of trial by judge or jury (Seling $v$. Young, 2001).

In Kansas, for example, a judge determines, during a hearing in which the offender is entitled to representation by counsel, whether probable cause exists to believe that the offender is an SVP (K.S.A. §59-29a05, 1994). If such a determination is made during the probable cause hearing, the alleged predator is transferred to a secure facility where a professional evaluation is completed (K.S.A. §59-29a05, 1994). Within 60 days following the probable cause hearing, a trial is conducted (K.S.A. §59-29a06, 1994). The individual, as well as the judge or attorney general, has a right to demand a jury trial. The individual may also retain, at the court's expense if necessary, a qualified expert or professional to conduct an evaluation (K.S.A. §59-29a06, 1994).

As referenced above, mental health testimony and/or report are influential, and often integral, components of the process of civilly committing a sex offender. Despite the heavy reliance on expert evidence, ultimately, the judge or jury determines whether the offender is eligible for postsentence civil commitment. While a clinician may, for example, function as a consultant to a court by providing expert testimony concerning an offender's observed irrational thought processes or behavioral impulsivity, clinicians have typically been dissuaded from addressing the ultimate question of whether an offender qualifies for a particular legal status (see Melton, Petrila, Poythress, \& Slobogin, 1997). Under the Federal Rules of Evidence and in jurisdictions adhering to a similar standard, clinicians are barred from offering conclusory opinions regarding mental state or condition, where it constitutes an element of the crime charged or of a defense thereto (Melton et al., 1997). As mentioned above, however, not only is such testimony often expressly proscribed, but with regard to volitional impairment in particular, a clinician would not have any indication of what to base such testimony upon without direction from the court as to how it is defining volitional impairment.

Moreover, it is well established both in case law and the mental health literature that clinical and legal meanings of mental illness are not synonymous. The use of diagnostic labels for legal purposes has been criticized on the grounds that they are descriptively imprecise (Slobogin, Melton, \& Showalter, 1984). Although potentially helpful in determining whether a pattern of behavior meets a legal threshold, diagnostic labels should not be considered dispositive of a legal issue (Slobogin et al., 1984). For example, in McDonald v. United States (1962), the D.C. Court of Appeals noted, "What psychiatrists may consider a 'mental disease or defect' for clinical purposes, where their concern is treatment, may or may not be the same as mental disease or defect for the jury's purpose" (see, also, Washington v. United States, 1967). The Diagnostic and Statistical Manual of Mental Disorders, Fourth Edition (DSM-IV; APA, 1994), explicitly states that the inclusion of diagnostic categories, such as pedophilia, does not imply that the conduct meets legal criteria for what constitutes mental disease and states further that these categorizations "may not be wholly relevant to legal 
judgments." Schopp and Sturgis (1995) differentiate between mental illness, as recognized in the mental health and legal arenas, noting that mental illness in the mental health arena generally refers to an impairment in psychological processes, which may correspond to a formal diagnostic category, while mental illness in the legal arena is a mental impairment rendering one ineligible for a particular legal status and the rights or liabilities commensurate with that status.

While stated clearly in the case law, diagnostic manuals, and professional literature, experts often have more difficulty limiting their role when involved in the evidentiary process. Indeed, Schopp and Quattrocchi (1995) note the responsibilities not only of clinicians in limiting their testimony but also of the attorneys in asking such questions to experts and of judges in allowing such questions and/or responses.

This is not to say, however, that there is no role for mental health professionals in the process. Quite the opposite, the training and experience of clinicians provides them with specialized knowledge that can assist courts in making the normative judgments as to whether particular legal criteria are met. Clinicians can offer descriptive and explanatory testimony relevant to an offender's impairment, and the relationship between that impairment and the criminal conduct at issue (Schopp \& Sturgis, 1995). Undoubtedly, there is utility to clinical expertise when it provides thorough description of clinicians' unique understanding of human behavior. The court then makes the normative judgment as to whether such impairment, as described by the mental health professional, renders the individual eligible (or ineligible) for a particular legal status (Schopp \& Sturgis, 1995). Undeniably, the application of the relevant legal criteria has the potential of being aided by the specialized knowledge of mental health professionals (Bonnie, 1984).

\subsection{A brief history of the insanity defense and volitional impairment}

Given that courts have long struggled with defining volitional impairment in the insanity context, a brief history of the struggle in this alternative mental health domain deserves mention. Since the earliest codification of a criminal responsibility standard in M'Naghten (M'Naghten's Case, 1843), courts have grappled with attempts to formulate meaningful insanity standards. The M'Naghten test was purely cognitive, focusing solely on whether the defendant had knowledge of the nature and quality of the criminal act and whether he knew that act was wrong (Melton et al., 1997). Criticizing the M'Naghten test as too narrow, an "irresistible impulse" rule was formed, which broadened the standard to include severe volitional impairment in individuals who were otherwise aware of the wrongfulness of their actions (Parsons v. State, 1886). However, this test also met resistance, as it required total cognitive or volitional incapacity, in an era where such absolutist views were considered increasingly outdated and irrelevant (Ogloff, Roberts, \& Roesch, 1993). More importantly, distinguishing between an irresistible impulse and an impulse not resisted proved to be exceedingly difficult (Rogers \& Shuman, 2000).

In 1962, the American Law Institute (ALI) published its Model Penal Code, in which a new insanity defense standard was drafted. The ALI formulation included both volition- 
al and cognitive components: "A person is not responsible for criminal conduct if at the time of such conduct as a result of mental disease or defect he lacks substantial capacity either to appreciate the criminality of his conduct or conform his conduct to the requirements of the law" (Melton et al., 1997, p.192). The term "substantial capacity" seemed to allow something less than total cognitive or volitional impairment. Although once widely popular in a majority of U.S. jurisdictions, this standard fell into public disfavor after John Hinckley, who attempted to assassinate President Reagan, was found not guilty by reason of insanity under it (Ogloff et al., 1993). The Hinckley acquittal fueled a growing controversy regarding the volitional prong of the ALI. Indeed, both the American Bar Association (ABA; 1983) and the APA (1983) advocated for the abolition of the volitional prong, asserting that less consistent application of the insanity defense would result from utilizing such an imprecise standard (Melton et al., 1997). Quite aptly, the APA issued the following statement:

\begin{abstract}
The line between an irresistible impulse and an impulse not resisted is probably no sharper than that between twilight and dusk. . .The concept of volition is the subject of some disagreement among psychiatrists. Many psychiatrists therefore believe that psychiatric testimony (particularly that of a conclusory nature) about volition is more likely to produce confusion for jurors than is psychiatric testimony relevant to a defendant's appreciation or understanding (p. 685).
\end{abstract}

The ABA (1983) similarly criticized volitional tests by noting that there is still no valid or reliable basis for measuring capacity for or impairment of self-control. Prior to becoming a Supreme Court Justice, Warren Burger commented that the irresistible impulse label has "always been a misleading concept because it has connotations of some sudden outburst of impulse and completely overlooks the fact that people do a lot of weird and strange and unlawful things as a result of not just sudden impulse but long brooding and disturbed emotional makeup" (Melton et al., 1997, p. 201). As a result of these and other criticisms, the ALI formulation gradually began to fall out of use, with more states returning to some variation of the strictly cognitive M'Naghten test (Melton et al., 1997).

Indeed, the lack of objective criteria on which to make a judgment regarding whether an impulse is truly irresistible or simply not resisted has been troubling (Melton et al., 1997). Bonnie (1984) argues that volitional clauses increase psychiatric disagreement and error as there is "no way to calibrate the degree of impairment of behavior controls" (p. 17). Indeed, Bonnie suggests that because we do not have objective methodology for determining volitional impairment, litigation is often reduced to subjective moral guesses. Melton et al. (1997), in their seminal text, sum up the discussion of the volitional prong in the insanity defense by noting that its scope is "extremely vague" (p. 201). Notably, the argument that we are not able to measure volitional impairment accurately is at the heart of much of this criticism (e.g., ABA, 1983; Bonnie, 1984). What is often ignored, however, is a definition of volitional impairment. Undeniably, to calibrate a measure of volitional impairment would first require operationalization of the notion of self-control. Nevertheless, it is curious that the Supreme Court would require volitional impairment in Crane, given the widespread criticism of volitional impairment prongs in the insanity context. 


\section{Attempts to define volitional control}

\subsection{Case law}

In 1994, Minnesota adopted a "sexual psychopathic personality" law, recodified from a 1939 "psychopathic personality" law (Minn. Stat. §253B.02, subd. 18b [Supp. 1997]). The Legislature defined a sexually dangerous person as one who evidences a habitual course of misconduct in sexual matters and an utter lack of power to control sexual impulses, which makes that person a danger to others (Minn. Stat. §253B.02, subd. 18b [Supp. 1997]). Minnesota, through recent cases, has brought some clarity to the idea of lack of volitional control. In In re Patterson (1995), the Minnesota Court of Appeals rejected a literal interpretation of lack of volitional control offered by a psychologist who "limited his definition of lack of control only to those very extreme examples of persons who had cognitive deficits arising from conditions such as severe mental retardation, dementia, or organic brain damage." Similarly, in In re Kunshier (1995) the court rejected the premise that evidence for loss of control be limited to only "those individuals who suffer conditions such as psychosis, sleep walking, or brain seizures."

Under Minnesota law, planning or grooming behavior (i.e., conduct intended to select and prepare potential victims) by a sexual offender does not necessarily preclude a finding of utter lack of power to control sexual impulses (Held, 1999). While the Linehan I (1994) and In re Schweninger (1994) courts considered evidence of planning and grooming to be inconsistent with a finding of lack of volitional control, other Minnesota courts have found the utter lack of power to control standard to be met, even where an offender had engaged in grooming (In re Bieganowski, 1994; In re Adolphson, 1995), where the offender's acts were characterized by a "fair amount of planning and deliberateness" (In re Pirkl, 1995) and where the offender's actions were “deliberate to some degree” (In re Mayfield, 1995).

Several Minnesota decisions have also revealed that an offender's lack of insight may be relevant to a finding of lack of volitional control. In re Irwin (1995) noted that "without this basic insight [into his problem], appellant has the utter lack of control." In In re Adolphson (1995), the court found that the offender met the utter lack of power to control standard due to his "entrenched belief" in the acceptability of sexual activity with minors.

Related decisions have clarified that constant or total lack of control is not necessary. Rather, loss of control might be situational (In re Pirkl, 1995; In re Mattson, 1995) and may predictably result from the removal of external controls (In re Toulou, 1994). Moreover, an offender need not exhibit lack of control all the time (In re Irwin, 1995; In re Toulou, 1994).

Repeated misconduct despite negative consequences might be relevant to the understanding of inability to control (Held, 1999). In In re Kunshier (1995), the court gave considerable weight to evidence showing that the offender's "impulses override any normal fear of capture or consequences," in finding that the offender was dependent upon incarceration to control his sexual impulses. Another court (In re Mattson, 1995) noted that "when a person engages in behavior despite repeated consequences, it evidences a lack of control." Moreover, the In re Crocker (1997), the court considered as evidence of lack of control the fact that an 
offender engaged in criminal behavior even when it was very foreseeable that he would be caught. In People v. Martinez (2001), in determining that a repeat rapist qualified as an SVP, a California Appellate Court gave weight to the psychologist's assertion, "when you engage in these kinds of crimes and you're in custody for another rape, one wonders if you are at all able to exert any control over sexual deviant fantasies and urges," despite that the defense's expert witness found no evidence that the defendant was volitionally impaired, noting that the defendant "knew what he wanted and intentionally acted to get it."

Unpredictability has also been considered relevant to volitional impairment. In the concurring opinion of Westerheide v. Florida (2000), it was suggested that acts of free choice would likely be unpredictable, while avolitional acts (by reason of mental abnormality or personality disorder) would be more predictable, if based upon diagnostic criteria proved to be reliable and valid.

Unfortunately, where definition has been given regarding volitional impairment, the definition has been vague. In Westerheide v. Florida (2000), the court defined volitional for the purpose of an SVP hearing to mean an "act of will or choosing the act of deciding or the exercise of will." No satisfactory legal definition exists, however, that precisely articulates the kinds of impairment or psychological dysfunction that qualify as volitional impairment.

While these cases give some indication of what may be relevant to an inability to control standard (e.g., repeated misconduct despite consequences, lack of insight, predictability) as well as what is not necessarily required for volitional impairment (e.g., total or constant volitional impairment, "true" volitional impairment, such as seizure disorder), the information provided is generally less than satisfactory. Not only is there no clear articulation of what qualifies as inability to control, but also, court opinions often seem contradictory in nature (e.g., evidence of planning or grooming behavior). In sum, analysis of these cases reveals little about what is meant by the notion of volitional impairment and may serve only to confuse the courts or mental health experts further.

\subsection{Legal theory}

Volitional control, often as it relates to the insanity defense, has been the subject of much discourse in the legal arena. Schopp (1991) offered two interpretations of the idea behind volitional control standards. In the literal interpretation, an individual lacks control over his or her behavior if that person is literally unable to direct movement (or lack of movement) through decision (Pelayo, 1999). Such inability might occur through epilepsy, stroke, or other neurological impairment. For example, while skiing, a person might suffer a stroke causing temporary paralysis in his legs. While this skier may observe persons in his path and be consciously aware that he is running over them, his decision process is unable to control his legs so as to avoid hitting another skier.

In a more flexible interpretation of volitional standards, Schopp (1991) considers that there are degrees to which behavior is controlled. Under this flexible standard, an offender may lack control over his behavior when it would be unreasonable to expect him to perform (or not per- 
form) a certain act under his or her particular circumstances (Schopp, 1991). While this explanation of a more flexible standard helps to provide some insight into the importance of circumstance and may be the type of volitional impairment that the Crane Court is referring to, we still lack a clear and shared understanding of the types of circumstances under which it would be unreasonable to expect a sex offender to exert control over sexually deviant conduct.

Morse (1994), in commenting on the complicated nature of "control" excuses, identified several self-protective variables that he described as helping one exercise control over one's actions. These include self-awareness/self-monitoring, fear of consequences, rationality (including accurate perception and appropriate reasoning), desire for moral behavior, control over emotions, capacity for empathy, self-control (i.e., ability to suppress desires), and finally, good judgment or practical wisdom. Morse urges that when determining blame (or lack thereof) for wrongdoing, it is helpful to consider the degree to which a person possesses these self-protective variables.

Morse (1994) further recommends that in making normative decisions concerning a person's blameworthiness, the fact finder should consider that the possession of these selfprotective variables is "mostly a function of hereditary and environmental factors during childhood and adolescence that were not determined by the agent" (p. 1609). While not suggesting that we use these variables to excuse behavior, Morse does suggest that we consider these factors when making judgments, as it will give us a sense of how difficult it was (or was not) for this person to "fly straight" (p. 1610).

Rachlin, Halpern, and Portnow (1984), "with a certain amount of hubris," sought to undertake the challenge of differentiating between an irresistible impulse and an impulse not resisted. Their framework for distinguishing these acts came in response to the APA statement referred to above (regarding the line between an irresistible impulse and an impulse not resisted, being no sharper than that between twilight and dusk). Individuals unable to resist an impulse must act to alleviate "otherwise overwhelming anxiety" (Rachlin et al., 1984). They are viewed as overcontrolled obsessive-compulsive individuals whose impulses are generally ego-dystonic, unwanted, intrusive, and/or irrational. Indeed, Rachlin et al. stress that it is the futility or absurdity of the rituals (often checking, cleaning, avoiding, or repeating) that is a "critical diagnostic element." Alternatively, those individuals who are able to resist impulses, but choose otherwise, are viewed as generally immature and are unlikely to enter treatment voluntarily (unlike their counterparts who are likely to be treatment seeking). The action engaged in is typically ego-syntonic and pleasurable. Moreover, the purpose is typically clear, as the individual benefits somehow from the behavior.

While this definition reflects, to some degree, the distinction between the DSM-IV (APA, 1994) impulse control and obsessive-compulsive disorders, it is not readily apparent that this distinction would assist in the determination of an offender's ability or inability to control conduct, as articulated by the Hendricks Court. It is also not clear why this interpretation of inability to control would justify either exculpation under an insanity defense or commitment under sexual predator statutes. Indeed, with regard to the sexual predator legislation, the justificatory significance of using this interpretation to distinguish those appropriate for commitment from those more appropriately dealt with through criminal justice proceedings is unclear. Finally, the reference to overwhelming anxiety suggests that the authors may have 
simply relocated the question. That is, if "overwhelming" means that which the individual is unable to control or resist, the interpretation is vacuous because it merely rephrases the question. Moreover, with regard to the nature of the impulses, it is worth noting that some pedophiles experience both pleasure from the sexually abusive act and from the ego-dystonic remorse following the act, sometimes enough to seek treatment in the absence of criminal justice system involvement. The authors, of course, acknowledge that theirs is a theoretical delineation, which may or may not have relevance to legal questions.

The discussion of Schopp (1991) of volitional impairment reflects the varied legal theories about this notion. On the one hand, some theorists appear to employ a literal interpretation of volitional impairment, including only those acts that are not willed muscular contractions (see, e.g., Pelayo, 1999). On the other hand, some theorists appear to utilize a flexible interpretation of volitional impairment (e.g., Morse, 1994; Rachlin et al., 1984), considering factors, such as certain self-protective variables, anxiety, or the extent to which impulses are unwanted, as central to the notion of volitional impairment. In sum, legal theorists appear less than consistent in discussing volitional impairment. Some conceptualize the notion in the pure sense, focusing on the ability to direct movement through decision. Others seem to conceptualize something less than true volitional impairment, recognizing that there are certain factors or circumstances that may help or hinder one from controlling conduct.

\subsection{Psychological/criminological theory}

One of the most influential crime theories to date is that of Gottfredson and Hirschi (1990), who argue that the lack of self-control is the broadest and most important cause of crime (Baumeister \& Boden, 1998). The central idea behind Gottfredson and Hirschi's general theory of crime is that a deficit in self-control, which is theorized to be an inborn trait, whose manifestation relates to ineffective child rearing, increases the propensity of individuals to commit crime. The authors posit that persons lacking in self-control "tend to be impulsive, insensitive, physical (as opposed to mental), risk-taking, short-sighted, and nonverbal, and they will tend therefore to engage in criminal and analogous acts."

In the culpability model of Alicke (2000), personal control is assumed to vary quantitatively rather than qualitatively, allowing for gradations of personal control. Alicke suggests that desire and foresight are central, reasoning that volitional control is enhanced when consequences are anticipated and desired, although diminished when consequences are neither foreseen nor desired. Alicke further suggests that greater self-control is likely where one has enacted an elaborate scheme, or otherwise planned thoroughly, as opposed to having acted impulsively.

Baumeister and Boden (1998) argue that breakdowns in self-control (or self-regulation) processes are at the root of most violent acts. They posit that self-control can be understood as the ability to prevent oneself from responding in a certain way or the ability to refrain from tendencies that would otherwise occur. Failure of self-control is theorized to have three primary causes: (1) when individuals hold conflicting internal standards (e.g., finding it difficult to act violently in a situation where it is expected, such as war); (2) where there is inhibited self-monitoring or self-awareness; and (3) where there is lack of strength to control aggressive impulses. The authors report that this third cause is less well understood, being 
that it is unknown why aggressive impulses at times overcome the capacity for self-regulation. Indeed, this third cause may simply be restating the claim of low self-control, which of course, seems not to be very well understood.

Baumeister and Boden (1998) also discuss the distinction between failure and abandonment of self-control, opining that "the notion of irresistible violent impulses seems to be a self-serving construction of defense lawyers and of perpetrators wishing for forgiveness rather than a psychological fact" (p. 130). They understand most criminal acts to occur through acquiescence, or a choice to abandon self-control, and cite as support instances of offenders turning on and off their aggressive actions through rational thought. They do not, however, offer explanation of the impairment involved in failure (as opposed to abandonment) of self-control.

Baumeister and Heatherton (1996) suggest that persons typically act during a "moment of weakness," as opposed to being driven by irresistible impulses (p. 13). Furthermore, they posit that self-control is a limited resource, breaking down as a result of fatigue, overexertion, or stress, although strengthening through the regular practice of impulse control. Indeed, it has been argued that self-control operates like a muscle, becoming weaker after exertion, replenishing with rest, and slowly becoming stronger with repeated exercise (Baumeister \& Exline, 2000). This discussion of the limits or tendencies of self-control would, of course, be more helpful if there existed a clear explanation of the notion of volitional impairment.

Hare (1993) discusses "poor behavioral controls" as central to psychopathic behavior, noting that criminals often have weak inhibitory controls that are overcome with only slight provocation (p. 59). Despite their "hair trigger" impulsive responses, however, Hare opines that psychopaths are not out of control because they know exactly what they are doing (p. 60). Hare implies that although psychopaths often choose to "blow their stack" in response to situations, they are in complete control while doing so (e.g., rationally deciding to sexually assault someone in a location where they will not be discovered; p. 60).

In summary, the psychological literature, similar with legal theory, provides mixed notions of self-control. However, most seem to imply that self-control varies along a quantitative dimension, that is, that there are degrees to which actors possess self-control and factors that may influence self-control. Moreover, while these psychological theorists seem to reject the notion of irresistible impulses, they also discuss gradations of self-control. Considering such gradations, it is not entirely clear why they typically view actors as abandoning self-control instead of veritably losing control, which perhaps could occur at the utmost gradation. What is clear is that mental health professionals seem to view the concept of self-control as very relevant to criminal behavior (e.g., Gottfredson \& Hirschi, 1990; Hare, 1993). Often, however, the notion of self-control, as discussed, seems to overlap with the typical qualities of criminal behavior, including impulsivity, risk taking, short sightedness, and low self-monitoring. Whether these psychological notions of self-control are relevant to the discussion of volitional impairment in the legal context is uncertain. At a minimum, they provide insight as to what psychologists view as relevant and, as such, are important to the extent that mental health professionals are frequently asked to provide testimony. 


\subsection{Psychological practice}

Hall (1985), noting the lack of operational criteria within the various legal tests of insanity, sought to provide evaluation guidelines to apply to forensic evaluations. He notes that "massive stress" and "certain organic conditions" may weaken behavioral controls (p. 13). Evidence of volitional capacity in his model includes instances of behavioral self-regulation. Hall provides an example of "changing the availability of a stimulus," whereby a person gives a weapon to another (fearing loss of self-control), to illustrate the point that self-control is, in fact, operating (p. 13). Hall also suggests that "doing something else" to prevent an expected response may be indicative of volitional capacity (p. 13). Thus, a sex offender who distances himself from a potential victim may be changing the availability of a stimulus in an exercise of volitional capacity. Similarly, an offender who avoids viewing child pornography, as he is familiar with his typical response to it, would be exercising self-control.

Rogers and Shuman (2000) attempted to translate legal standards into psychological concepts. In operationalizing volitional capacity, as it relates to the "irresistible impulse" test, they suggest that the "loss of power" to avoid doing the act addresses the inevitability and uncontrollability of the behavior (p. 73). However, there is no clear articulation provided regarding the point at which behavior becomes either inevitable or uncontrollable. Moreover, this seems to imply that we understand the process, although the definition remains ambiguous. They also suggest that clinical attention be given to the role of situational variables, temporary emotional states, and substance use in evaluating loss of control. Moreover, the authors direct attention to the defendant's attempts to resist or avoid the criminal behavior, implying that efforts at resisting impulses may be indicative of volitional impairment.

Rogers and Shuman (2000) also attempt to address the ALI volitional prong, suggesting that the phrase "conformity of conduct" refers to "any marked loss in self-determined purposive behavior at the time of the offense" (p. 79). Loss of behavioral control is often reported to be paralleled by loss of cognitive control, although the authors suggest that there may be situations where the defendants have cognitive awareness of their actions, although they lack the ability to control their behavior. Unfortunately, they do not specify what the key characteristics of these situations might be.

Rogers and Shuman (2000) suggest several factors as relevant to the ALI determination of volitional impairment. These include the defendant's perceived options, decision-making abilities, the deliberateness of the actions, and the point at which criminal actions become "inevitable" (p. 80). They further note that reckless or impulsive behavior, the defendant's self-reported volitional impairment, ritualistic behavior, and ineptness (i.e., bungled criminal activity) are not necessarily related to volitional impairment. They also stress that the ability of the accused to foresee and thus avoid situations where uncontrollability is likely to occur is relevant and must also be considered.

Webster and Jackson (1997), in offering a clinical perspective of "impulse-driven conduct," provide a sketch of the typical impulsive person. The following characteristics are enveloped in five domains: (1) interpersonal dysfunction: manipulative, black/white thinking with regard to others, distrustful; (2) lack of plans: avoidance of change, volatile lifestyle; (3) distorted self-esteem: low self-awareness, hopelessness, acting rashly to avoid emotion- 
al discomfort; (4) anger and rage: aggression, low frustration tolerance, high explosivity; and (5) irresponsibility: entitlement, beliefs that most others act immorally and irresponsibly, poor ability to cope with emotional discomfort. It is not clear from the description, however, when this impulse-driven conduct is resistible versus irresistible.

While some authors have attempted to provide guidelines or articulation relevant to volitional impairment, their operationalizations have been less than satisfactory. First, there is frequent reference to what may or may not qualify as volitional impairment (e.g., massive stress, certain organic conditions, impulsive behavior, and ineptness), although no author precisely defines the notion of volitional impairment, nor is there even precision or agreement as to which and in what capacity these factors reflect volitional impairment. Moreover, while some description seems to support the idea that we understand the process of how one loses control, there is no clear articulation of what this means. Finally, as with the theoretical literatures, there seems to be considerable overlap in the notions of impulsive criminal behavior and lack of self-control, such that volitional impairment may merely mean reckless or otherwise irresponsible behaviors.

\subsection{Empirical research}

On the whole, there has been little scientific evidence to show how volition operates, leaving the exploration of volition to be mostly theoretical in nature (Pelayo, 1999). However, some empirical research has attempted to examine the construct and perceptions of selfcontrol or how the construct of self-control relates to other variables.

Arneklev, Grasmick, and Bursik (1999) developed a scale to examine the six self-control components (impulsivity, avoidance of difficult tasks, risk-taking, tendency to be physical rather than mentally contemplative, self-centeredness, and bad temper) of the theory of crime of Gottfredson and Hirschi (1990). They found support for the theory, as the six dimensions did appear to coalesce into a global latent trait, and low self-control was found to be an invariant characteristic, remaining stable through time and social situations in their sample of 683 community members and undergraduates. However, the authors also found that the dimension of impulsivity seemed to be the most important dimension of the global construct, leaving them to ponder, "Is low self-control, to a large extent, simply impulsivity?" (p. 327). Although there appears to be some scientific support for the notion of Gottfredson and Hirschi, this construct would not necessarily comport with volitional impairment in the sexual predator or insanity context. Without a court-provided articulation, it is impossible to know the extent to which these notions intersect.

Another line of research has examined the relationship between mood and impulse control. Tice, Bratslavsky, and Baumeister (2001) found some evidence that mood regulation may override impulse control in the context of emotional distress, leading them to conclude that some people may purposively suspend self-control to escape from bad moods. However, the evidence regarding the role of affect and impulse control has been mixed (see, e.g., Tice $\&$ Ciarocco, 1998). Other research has shown that self-control in one area may undermine attempts at self-control in another area (see e.g., Baumeister, Bratslavsky, Muraven, \& Tice, 
1998; Muraven, Tice, \& Baumeister, 1998). However, in these studies, self-control has typically been operationalized as the ability to resist one's desire to do something that is expected to make one feel good (such as eating a savory snack). Indeed, the majority of self-control research has been related to gambling, drug or alcohol use, or eating behaviors.

Whether the processes that undermine self-control in the above situations are similar with those that undermine self-control with respect to sexual assaults or to criminal behavior generally remains uncertain. However, even if the lack of self-control regarding criminal behavior involves processes similar with the lack of self-control in these other domains (gambling, eating, etc.), there is no apparent reason to think that lack of self-control in this sense constitutes the inability to control for the purpose of criminal responsibility or sexual predator commitment. Indeed, this lack of self-control seems to refer to competing desires, such as the choice over an immediate strong desire for candy versus a longer term desire to lose weight. It is not apparent why acting on one's current strongest desire should be a legal basis for civil commitment as a sexual predator or for the purpose of exculpation under an insanity defense.

Burton, Cullen, Evans, Alarid, and Dunaway (1998), in a study finding that self-control accounted for the gender gap in criminal conduct, operationalized the construct of self-control of Gottfredson and Hirschi (1990) on a 12-item scale, including items assessing frustration tolerance, desire for immediate gratification, patience, preference for risk, and tendency to be physical versus mentally contemplative. Finding further support for the hypothesis of Gottfredson and Hirschi, their operationalization of low self-control showed a significant relationship with self-reported crime and other self-reported imprudent behaviors in a sample of 555 community residents.

Shively (2001), in a vignette study examining perceived level of self-control among sexual aggressors, found that most participants attributed high levels of self-control to the aggressors across situations. The only variable statistically altering the participants' ratings of perceived control was alcohol consumption. Shively found no support for other contextual variables (e.g., amount of foreplay, aggressor's use of force, and victim's resistance). Thus, it seems that laypersons are unlikely to view aggressive sexual impulses as irresistible, except perhaps where substance use is involved.

As noted, the empirical research examining how volition operates has not been with sexual predators, thus, it is not certain how relevant such research is to this specific legal context. Once again, there is overlap between the notion of impulsive or antisocial conduct and the lack of self-control, as empirical researchers have not only included impulsive or risk-taking behaviors in their operationalizations of self-control, but also have found that this impulsivity seems to reflect a primary dimension of the self-control construct. Finally, it is apparent that although researchers seem to consider self-control as highly relevant to the commission of crime, there is rarely an adequate definition of what is meant by the term self-control.

In sum, there does not appear to be a consistent notion of volitional impairment or low self-control in the theoretical or empirical literatures, nor in psychological practice guidelines. Instead, there is pervasive vagueness and uncertainty, with a clear definition rarely given. Despite this lack of clarity, at least one theme is apparent. Across all domains, there appears to be divergence with regard to whether one is considering literal or true volitional impairment (irresistible impulse) as opposed to some lesser type of impairment, merely consti- 
tuting an impulse not resisted. Generally, among those adhering to the former standard, there seems to be little support for the notion of volitional impairment, where it encompasses anything less than truly unwilled movement. Among those adhering to a more flexible interpretation of volitional impairment, there is little consensus as to what types of factors support or undermine the notion of volitional impairment, with one exception. In discussing the components of lack of control, lawmakers, theorists, researchers, or professionals seem to consistently confuse the notion of impulsive conduct with the notion of uncontrollable behavior. Indeed, among those discussing lack of control in this flexible sense, the exception to the general lack of consensus is that there is substantial overlap with impulsive or generally reckless behavior.

This general divergence between literal and flexible interpretations of volitional impairment is consistent with the discussion of Schopp (1991), including the observation that the notion in the flexible sense is less amenable to counter examples precisely because it is vacuous. When looked at carefully, the notion of volitional impairment in the flexible sense usually reduces to the claim that a person is not able to control his conduct if he suffers some impairment such that it renders him unable to control his conduct. Without clear discussion as to the nature of the impairment, however, it is impossible to separate out those offenders appropriate for commitment from those appropriate for the criminal justice system.

\section{Conclusion and recommendations}

While the Crane decision requires some evidence of volitional impairment to legitimize postsentence sex offender civil commitment schemes, we have little information on exactly what it means to be able to control one's conduct, other than subjectively defined loss of control or history of failure to control conduct, which the Supreme Court appeared to rely upon in Hendricks. Indeed, the Hendricks record indicated no evidence of literal volitional impairment, in that Hendricks seemed effectively able to control his actions through decision, nor is there evidence to suggest that the court relied upon factors other than Hendricks' repetitive pattern of criminal misconduct. Unfortunately, nowhere in the case does the Court precisely articulate what is meant by this notion of volitional impairment. As the idea of volitional control has long been a highly confused concept, not only in the courts but also in the realms of psychological and legal literatures, it is curious why the Supreme Court would invite return to this often vaguely defined notion through Crane.

Following Crane, the evaluation of an offender's volitional capacity will be increasingly important for decision making concerning SVPs. Indeed, mental health professionals will likely be asked to provide testimony or report relative to whether an individual is able to control his or her behavior. Unfortunately, clinicians have no meaningful understanding of the mental components underlying individual control. Legal precedent, theoretical literatures, empirical research, and practice guidelines all lack clear operationalizations or conceptions of the criteria relevant to volitional impairment. Instead, there is pervasive ambiguity and uncertainty, with frequent overlap between the notions of impulsive behavior and low self-control. 
This ambiguity in the meaning of volitional impairment may raise a number of ethical concerns. Section 2.04 of the Ethical Principles of Psychologists and Code of Conduct (APA, 2002) mandates that professional judgments be based upon "established scientific and professional knowledge." Similarly, Section III.A of the Specialty Guidelines for Forensic Psychologists (Committee on Ethical Guidelines for Forensic Psychologists, 1991) advises that "forensic psychologists provide services only in areas of psychology in which they have specialized knowledge, skill, experience, and education." Because there is a lack of meaning with regard to the notion of volitional impairment, there is, of course, no generally accepted methodology for evaluating loss of control and/or making such judgments. Indeed, the use of typical assessment techniques would likely be inappropriate under Section 9.02 of the APA principles, given that no techniques have been developed for such application. Thus, a psychologist who provides testimony or report might be practicing out of the bounds of his or her competence if he or she rendered a judgment about the presence (or absence) of such impairment absent some generally accepted definition of the notion and well-conceived manner in which to measure such a notion. Additionally, the principle of nonmaleficience ("do no harm") applies. Undoubtedly, a psychologist who provides testimony or report about a particular defendant's ability to control behavior has a serious risk of causing harm (i.e., indefinite commitment as a SVP) where such testimony is not based upon legitimate expertise on the specific matters at issue (see Section III.B of the Specialty Guidelines for Forensic Psychologists). Given the stakes of indefinite commitment, psychologists have an ethical obligation to practice within the scope of their competence and acknowledge the limits of the profession.

With regard to court-solicited testimony or report, clinicians could certainly describe symptom patterns and client characteristics but would be unable to offer information distinctively relevant to volitional capacity, as the construct's definition remains ambiguous. In consideration of this persistent ambiguity, mental health professionals should limit their testimony to descriptive explanation of behavior, while the courts likewise need to examine carefully the parameters of expert psychological testimony regarding volitional impairment, to insure that such testimony meets applicable evidentiary standards.

\section{References}

Alicke, M. D. (2000). Culpable control and the psychology of blame. Psychological Bulletin, 126, 556-574.

American Bar Association. (1983). Model code of professional conduct. Chicago, IL: Author.

American Psychiatric Association. (1983). American Psychiatric Association statement on the insanity defense. American Journal of Psychiatry, 140, 681-688.

American Psychiatric Association. (1994). Diagnostic and statistical manual of mental disorders (4th ed.). Washington, DC: Author.

American Psychiatric Association. (1999). Dangerous sex offenders: A task force report of the American Psychiatric Association. Washington, DC: Author.

American Psychological Association. (2002). Ethical principles of psychologists and code of conduct. American Psychologist, 57(12), 1060-1073.

Arneklev, B. J., Grasmick, H. G., \& Bursik, R. J. (1999). Evaluating the dimensionality and invariance of "low self-control". Journal of Quantitative Criminology, 15, 307-331.

Baumeister, R. F., \& Boden, J. M. (1998). Aggression and the self: High self-esteem, low self-control, and ego threat. In R. G. Geen, \& E. Donnerstein (Eds.), Human aggression: Theories, research, and implication for 
social policy ( pp. 111-138). New York: Academic Press.

Baumeister, R. F., Bratslavsky, E., Muraven, M., \& Tice, D. M. (1998). Ego depletion: Is the active self a limited resource? Journal of Personality and Social Psychology, 74, 1252-1265.

Baumeister, R. F., \& Exline, J. J. (2000). Self-control, morality, and human strength. Journal of Social and Clinical Psychology, 19, 29-42.

Baumeister, R. F., \& Heatherton, T. F. (1996). Self-regulation failure: An overview. Psychological Inquiry, 7, 115.

Bonnie, R. J. (1984). Morality, equality, and expertise: Renegotiating the relationship between psychiatry and the criminal law. Bulletin of the American Academy of Psychiatry and Law, 12, 5-20.

Burton, V. S., Cullen, F. T., Evans, T. D., Alarid, L. F., \& Dunaway, R. G. (1998). Gender, self-control, and crime. Journal of Research in Crime and Delinquency, 35, 123-147.

Committee on Ethical Guidelines for Forensic Psychologists. (1991). Specialty guidelines of forensic psychologists. Law and Human Behavior, 15(6), 655-665.

Gottfredson, M., \& Hirschi, T. (1990). A general theory of crime. Stanford, CA: Stanford University Press.

Hall, H. V. (1985). Cognitive and volitional capacity assessment: A proposed decision tree. American Journal of Forensic Psychology, 3, 3-17.

Hare, R. D. (1993). Without conscience: The disturbing world of the psychopaths among us. New York: The Guilford Press.

Held, A. (1999). The civil commitment of sexual predators-Experience under Minnesota's law. In A. Schlank, \& F. Cohen (Eds.), The sexual predator: Law, policy, evaluation, and treatment ( pp. 2-1-2-54). New Jersey, USA: Civic Research Institutes.

In re Adolphson, No. C5-95-533 (Minn. Ct. App. July 25, 1995) (unpublished).

In re Bieganowski, 520 N.W.2d 525 (Minn. Ct. App. 1994).

In re Crane, 269 Kan. 578, 7 P.3d 285 (Kan. 2000), Cert. granted, U.S., 121 S. Ct. 1483, 149 L.Ed. 2d 372 (2001).

In re Crocker, No. C7-97-604 (Minn. Ct. App. Aug. 19, 1997), Sum. aff'd (Jan. 21, 1997) (unpublished).

In re Hendricks, 912 P.2d 129 (Kan. 1996).

In re Irwin, 529 N.W.2d 366 (Minn. Ct. App. 1995).

In re Kunshier, No. C7-95-1490 (Minn. Ct. App. Nov. 21, 1995) (unpublished).

In re Linehan, 594 N.W.2d 867 (Minn. 1999).

In re Mattson, No. C5-95-452 (Minn. Ct. App. June 20, 1995) (unpublished).

In re Mayfield, No. C2-95-103 (Minn. Ct. App. May 2, 1995) (unpublished).

In re Patterson, No. C3-95-935 (Minn. Ct. App. Sept. 19, 1995) (unpublished).

In re Pirkl, 531 N.W.2d 902 (Minn. Ct. App. 1995), Rev. denied (Minn. Aug. 30, 1995).

In re Schweninger, 520 N.W.2d 446 (Minn. Ct. App. 1994), Rev. denied, (Minn. Dec. 12, 1997).

In re Toulou, No. C9-94-993 (Minn. Ct. App. Nov. 1, 1994) (unpublished).

In re Young, 122 Wn.2d 1, 857 P.2d 989 (Wash. 1993).

Janus, E. S. (2000). Sexual predator commitment laws: Lessons for law and the behavioral sciences. Behavioral Sciences and the Law, 18, 5-21.

Kansas v. Crane, 2002 WL 75609.

Kansas v. Hendricks, 117 S.Ct. 2072 (1997).

K.S.A. §59-29a02 (1994).

K.S.A. §59-29a05 (1994).

K.S.A. §59-29a06 (1994).

La Fond, J. Q. (2000). The future of involuntary civil commitment in the U.S.A. after Kansas v. Hendricks. Behavioral Sciences and the Law, 18, 153-167.

Linehan I, 518 N.W.2d 609 (Minn. 1994).

McDonald v. United States, 312 F.2d 847 (D.C. Cir. 1962). 
Melton, G. B., Petrila, J., Poythress, N. G., \& Slobogin, C. (1997). Psychological evaluations for the courts: A handbook for mental health professionals and lawyers (2nd ed.). New York: Guilford Press.

Minn. Stat. §253B.02, subd. 18b (Supp. 1997).

M'Naghten's Case, 10 Cl. \& F. 200, 8 En. Rep. 718 (H.L. 1843).

Morse, S. J. (1994). Culpability and control. University of Pennsylvania Law Review, 142, 1587-1660.

Morse, S. J. (1998). Fear of danger, flight from culpability. Psychology, Public Policy, and Law, 4, 250-267.

Muraven, M., Tice, D. M., \& Baumeister, R. F. (1998). Self-control as a limited resource: Regulatory depletion patterns. Journal of Personality and Social Psychology, 74, 774-789.

Ogloff, J. R. P., Roberts, C. F., \& Roesch, R. (1993). The insanity defense: Legal standards and clinical assessment. Applied \& Preventive Psychology, 2, 163-178.

Parsons v. State, 81 Ala. 577, 2 So. 854 (1886).

Pelayo, C. (1999). “Give me a break! I couldn't help myself!"?: Rejecting volitional impairment as a basis for departure under Federal Sentencing Guidelines section 5K2.13. University of Pennsylvania Law Review, 147, 729-769.

People v. Martinez, 88 Cal. App. 4th 465 (2001).

Pratt, J. (2000). Sex crimes and the new punitiveness. Behavioral Sciences and the Law, 18, 135-151.

Rachlin, S., Halpern, A. L., \& Portnow, S. (1984). The volitional rule, personality disorders and the insanity defense. Psychiatric Annals, 14, 139-147.

Rogers, R., \& Shuman, D. W. (2000). Conducting insanity evaluations (2nd ed.). New York: The Guilford Press.

Seling v. Young, 121 S.Ct. 727 (2001).

Schopp, R. F. (1991). Automatism, insanity, and the psychology of criminal responsibility: A philosophical inquiry. New York, NY: Cambridge University Press.

Schopp, R. F. (1998). Civil commitment and sexual predators: Competence and condemnation. Psychology, Public Policy, and Law, 4, 323-376.

Schopp, R. F., \& Quattrocchi, M. R. (1995). Predicting the present: Expert testimony and civil commitment. Behavioral Sciences and the Law, 13, 159-181.

Schopp, R. F., Scalora, M. J., \& Pearce, M. (1999). Expert testimony and professional judgment: Psychological expertise and commitment as a sexual predator after Hendricks. Psychology, Public Policy, and Law, 5, 120174.

Schopp, R. F., \& Sturgis, B. J. (1995). Sexual predators and legal mental illness for civil commitment. Behavioral Sciences and the Law, 13, 437-458.

Shively, M. (2001). Male self-control and sexual aggression. Deviant Behavior, 22, 295-301.

Slobogin, C., Melton, G. B., \& Showalter, C. R. (1984). The feasibility of a brief evaluation of mental state at the time of the offense. Law and Human Behavior, 8, 305-320.

Tice, D. M., Bratslavsky, E., \& Baumeister, R. F. (2001). Emotional distress regulation takes precedence over impulse control: If you feel bad, do it! Journal of Personality and Social Psychology, 80, 53-67.

Tice, D. M., \& Ciarocco, N. J. (1998). Inhibition and self-control. Psychological Inquiry, 9, 228-231.

Washington v. United States, 390 F.2d 444 (D.C. Cir. 1967).

Webster, C. D., \& Jackson, M. A. (1997). A clinical perspective on impulsivity. In C. D. Webster, \& M. A. Jackson (Eds.), Impulsivity: Theory, assessment, and treatment ( pp. 16-40). New York: The Guilford Press.

Westerheide v. Florida, 767 So. 2d 637 (2000). 